\title{
A Rare Case of Corrosive Gastric, Splenic \& Pancreatic Necrosis
}

\author{
Authors \\ Dr Ajay H.Bhandarwar ${ }^{1}$, Dr Saurabh Gandhi ${ }^{2}$, Dr Chintan B Patel ${ }^{3}$, Dr Nitin P Tiwari ${ }^{4}$ \\ ${ }^{1}$ Professor, Department of General,GI,HPB\& Minimal Access Surgery, Grant Medical College \& Sir JJ \\ Group of Hospitals, Byculla, Mumbai - 400008 \\ Email:abhandarwar@yahoo.com \\ ${ }^{2,3,4}$ Assistant Professor, Department of General,GI,HPB\& Minimal Access Surgery, Grant Medical College \\ \& Sir JJ Group of Hospitals, Byculla, Mumbai - 400008 \\ Email: saur1234@gmail.com ${ }^{2}$, patelium_iway@yahoo.co.in ${ }^{3}$,nitinnitin44@gmail.com ${ }^{4}$ \\ Corresponding Author \\ Dr Ajay H Bhandarwar \\ MS, FMAS, FIAGES, FAIS, FICS, FBMS, FLCS, Professor \& Unit Chief, Dept. of Surgery, \\ Division of General, GI, HPB, Minimal Access Surgery, Grant Medical College \& Sir JJ Group of \\ Hospitals, Mumbai - 400008, India
}

\section{Introduction}

A corrosive substance is one that causes destruction or damage to the living tissue on contact. They can be broadly classified as acids \&alkalis. These substances find a place largely in every industrial sector \& household. Many of the corrosives are easily available as cheap toilet cleaners in India. The mechanism of action of acids being coagulative necrosis while alkalis liquefactive necrosis. The degree $\&$ extent of injury depends on several factors like the type of substance, morphologic form, the quantity \& the intent. Although children account for $80 \%$ of accidental ingestion ${ }^{1}$, the ingestion in adults is more often suicidal in intent \& therefore tends to be grave. The mortality associated with ingestion ranges from $10-20 \%$ but can escalate to $78 \%$ with a suicidal intention ${ }^{2}$. The immediate life threatening cause is laryngeal burn \&oedema followed by the resulting acute respiratory distress $^{3,4,5}$.Corrosive agents cause extensive damage to the GI tract through the path it travels as well as surrounding region due to extravasation. In acute stage it can cause necrosis \& perforation while the late sequale of oesophageal\& antral stricture follows inadvertently. Combination of corrosive agents can accentuate further damage due to additional mechanisms like exothermic reaction. We present here an unusual case of acute gastric, pancreatic \& splenic necrosis due to corrosive acid intake.

\section{Case Report}

A 35 year old male working in a gold jewellery shop was brought to the emergency department of our hospital with a history of ingestion of approximately $200 \mathrm{ml}$ of combination of Nitric acid and Hydrochloric acid with suicidal intent 6 


\section{JMSCR Vol||3||Issue ||10||Page 7920-7923||October}

hours ago. The patient was evaluated by the Emergency Department \& General Surgeon. Patient was in a state of shock and altered state of consciousness. His $\mathrm{pH}$ had dropped down to 6.8, $\mathrm{HCO} 3-$ to $4.0 \mathrm{mmol} / \mathrm{L}$.Excessive salivation with charred tracking marks at the angle of mouth, neck \& abdomen was consistent with corrosive intake. Oral cavity examination revealed red swollen tongue \& mucosa.

Abdominal examination showed tenderness \& guarding in the epigastric region with a normal chest \& abdomen radiographs. Patient's blood investigations showed severe acidosis (6.8) \& leucocytosis. After initial resuscitative measures the patient complained of increased abdominal pain with similar abdominal examination findings. A repeated Chest radiograph showed free gas under the diaphragm. Patient was posted for emergency exploratory laparotomy. Intraoperative findings showed total gastric necrosis, pancreatic necrosis \& splenic necrosis (Fig.1) with perforation of the stomach (Fig.2). Foul smelling bile stained fluid was extracted from the peritoneal cavity which displayed omental tissue death(Fig.3). An intraoperative decision to perform total gastrectomy with splenectomy was taken and the continuity of the tract was maintained by performing Roux en Y esophageojejunal anastomosis. The pancreatic necrosis was managed by pancreatic necrosectomy with drainage and distal feeding jejunostomy for nutrition.

Patient expired on the $4^{\text {th }}$ postoperative day due to respiratory complications. The autopsy findings showed total pancreatic necrosis except the tail (Fig.4) and inflamed oedematous oesophageal mucosa with scattered necrotic patches (Fig.5).

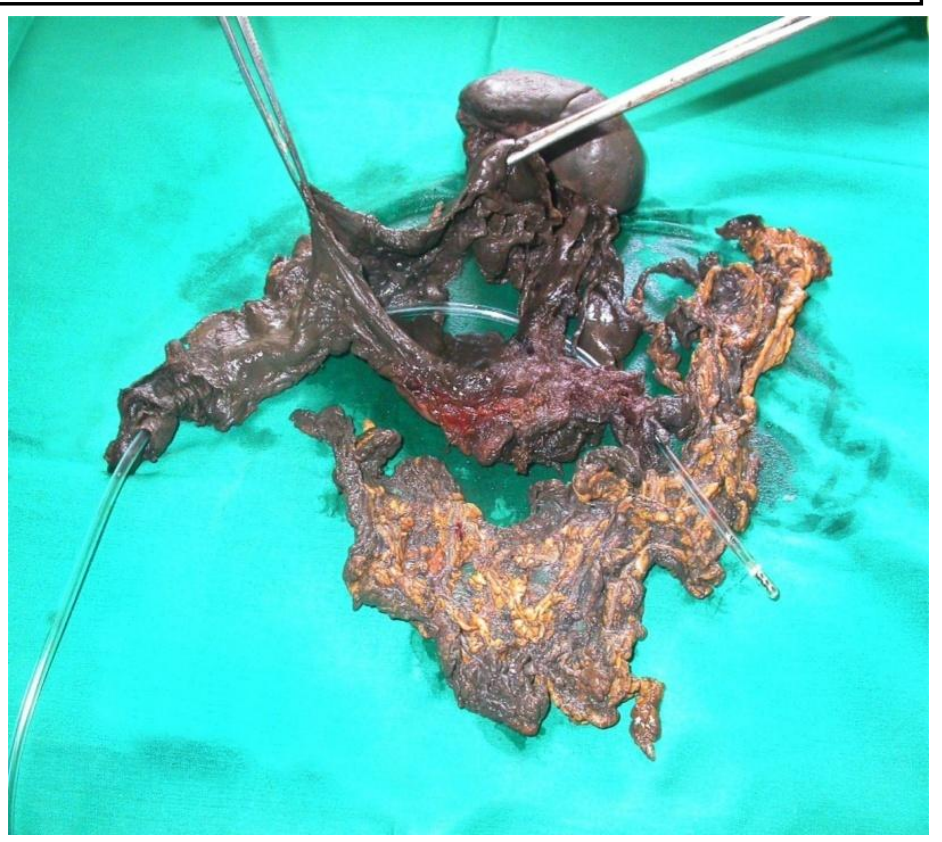

Figure1

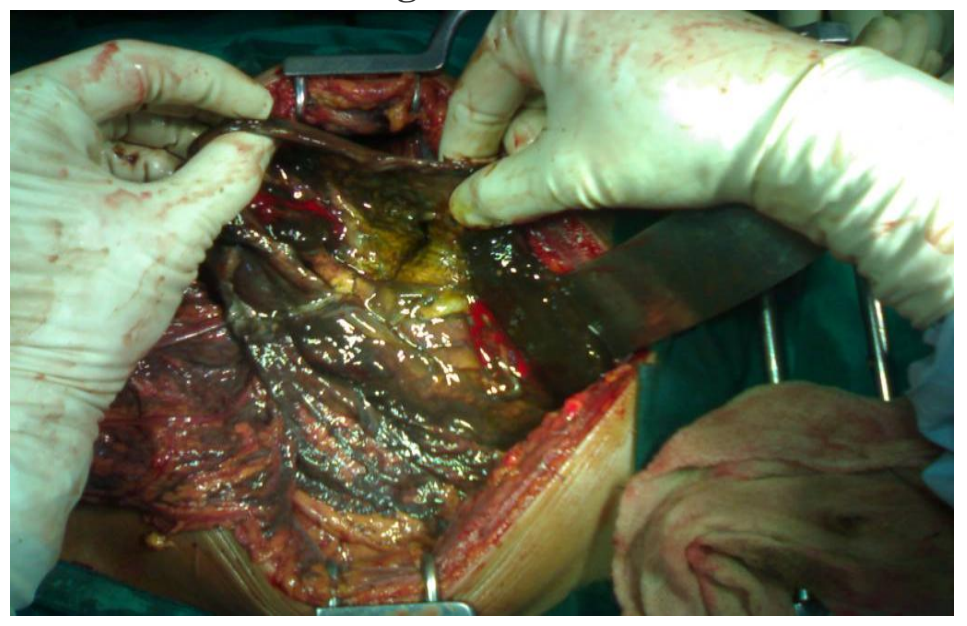

Figure2

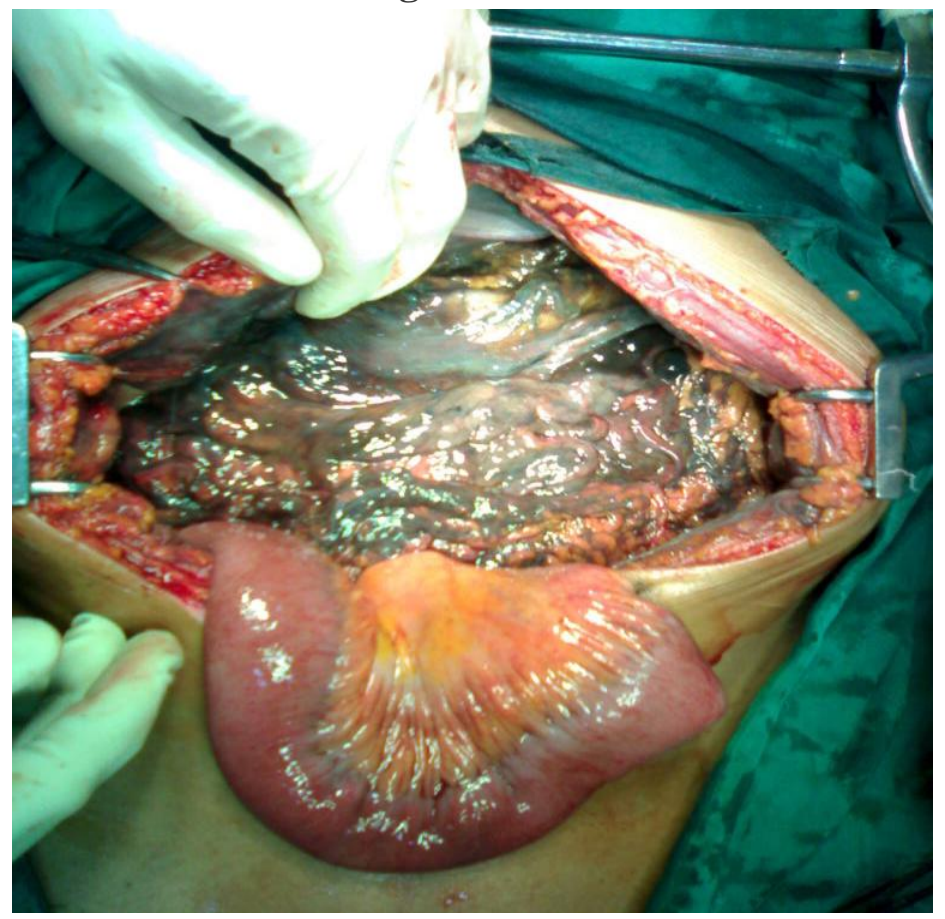

Figure 3 


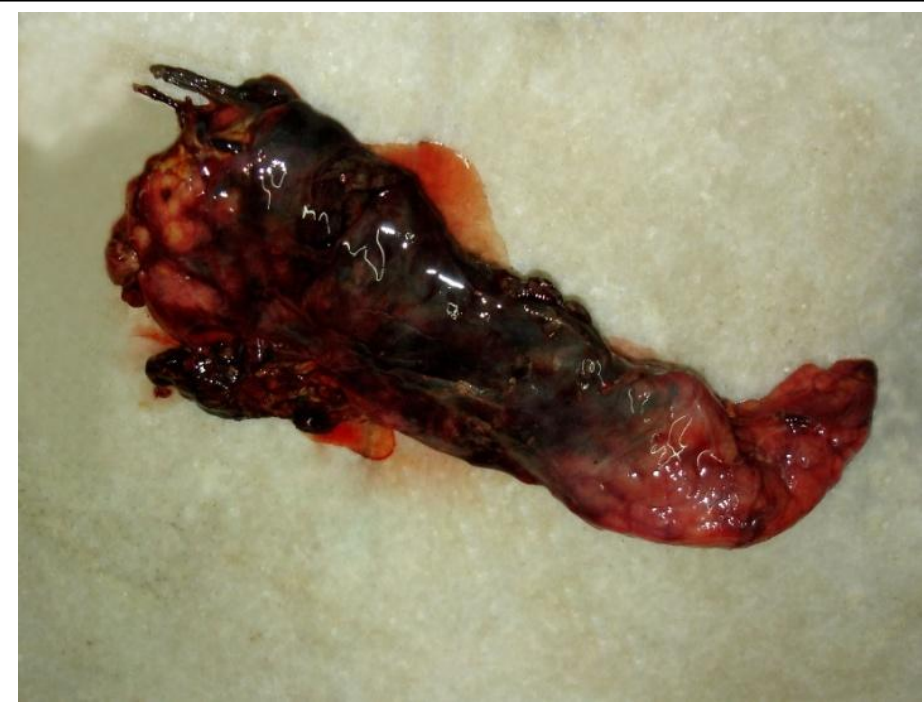

Figure 4

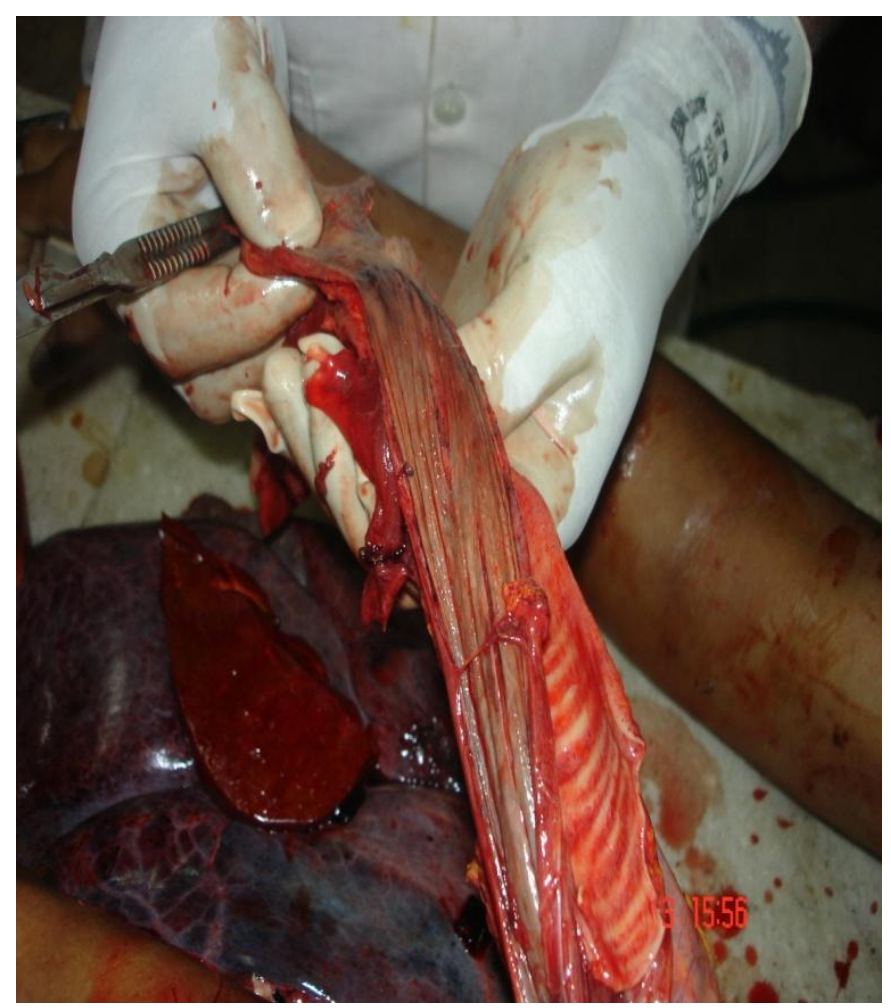

Figure 5

\section{Discussion}

The combination of Nitric Oxide \& Hydrochloric acid is also commonly known as Aqua regia which is a very strong corrosive agent used in various metal industries to dissolve metals. Solutions with $\mathrm{pH}$ less than 2 or greater than 12 are extremely corrosive. Acid induces coagulative necrosis while alkali liquefactive necrosis ${ }^{1}$. This coagulative necrosis forms a barrier for further tissue penetration compared to alkalis ${ }^{6}$.However, a larger amount or concentration of an acid can cause a significant tissue injury. This however is not only the major determinant of the extent of injury. The thrombosis of vessels \& heat production exacerbate the initial corrosive injury. Tissue injury progresses rapidly for first few minutes but can continue for several hours. Secondary infections can increase the morbidity\& mortality risks significantly. The portal for them can be stomatitis, pneumonitis, mediastinitis ${ }^{7}$

The extent of gastric injury appears to be related to the nature, volume \& concentration of the corrosive ingested. The length of the time the agent remains in contact with the stomach also has a direct proportional effect on the injury. Though the corrosive injuries to the stomach ranges from a spectrum of superficial mucosal injury to perforation, total necrosis of stomach as seen in our case is very rare. It may be due to strong nature of corrosive i.e.combination of Nitric Oxide \& Hydrochloric acid and amount ingested (200ml) The acid injuries are usually limited to stomach but 6-20\% patients have associated oesophageal\& small intestinal injury ${ }^{8}$. Necrotising pancreatitis has been reported in patients with transmural gastric necrosis, perforation of stomach $\&$ with involvement of duodenal mucosa ${ }^{9,10}$.

Necrosis of spleen due to acid corrosive agent either may be due to thrombosis of splenic vessels because of direct action of the corrosive agent or due to necrotising pancreatitis. The necrosis of stomach, spleen \& pancreas is further rare due to a corrosive injury.

Initial management in such patients is nothing by mouth, antacids and broad spectrum antibiotics. Intravenous fluids play an important role in the management. Blood transfusion is given when indicated. Coagulopathy \& metabolic acidosis can have a detrimental effect over the patient's management hence a close monitoring is required $^{11}$. A rapid preparation for mechanical ventilation is essential. A Chest Radiography with both domes of diaphragm can help ruling out a perforation. Fibreoptic endoscopy should be performed initially to determine the most proximal level of injury. It should be done with utmost care 
with imminent possibility of a perforation. Role of steroids is controversial with no added benefits in previous studies, on the contrary it can mask the developing signs of perforation ${ }^{12}$. Gastric lavage $\&$ emesis induction is contraindicated. An urgent surgical intervention is indicated for haemorrhage, free perforation or peritonitis. Removal of necrotic tissue is essential and may necessitate total gastrectomy, pancreatic oduodenectomy \& small bowel resection.

\section{Conclusion}

To conclude ingestion of a considerable amount of corrosive acid can lead to a significant damage to the gastrointestinal tract with greater effect in lesser quantity in cases of combination of corrosives. Repeated abdominal examination and Chest Radiography study can help in early diagnosis of perforation \& further surgical treatment. Early diagnosis \& intervention can salvage the patient by surgical \& supportive treatment.

\section{Conflict of interest: None}

Financial support: None

\section{References}

1. Gumaste VV, Dave PB, Ingestion of corrosive substances by adults. Am JGastroenterol. 1992; 87: 1-5

2. Ertekin C, Alimoglu O, Akyildiz H, Guloglu R, Taviloglu K. The results of caustic ingestions. Hepatogastroenterology. 2004;51:1397-400.

3. Cabral C, Chirica M, de Chaisemartin C, Gornet JM, Munoz-Bongrand N, Halimi $B$, et al. Caustic injuries of the upper digestive tract: A population observational study. Surg Endosc. 2012;26:214-221.

4. Franke DD, Davis EG, Woods DR, Johnson RK, Miller FB, Franklin GA, et al. Catastrophic gastrointestinal injury due to battery acid ingestion. J Emerg Med. 2011;40:276-9.
5. Ananthakrishnan N, Parthasarathy G, Kate $\mathrm{V}$. Acute corrosive injuries of the stomach: A single unit experience of thirty years. ISRN Gastroenterol 2011. 2011 914013.

6. Ellenhorn, M.J, Barceloux, D.G. in: Medical toxicology. Diagnosis and treatment of human poisoning.Elsevier Science, New York; 1988:924

7. Coskun Araz, Nedim Cekmen, Ozcan Erdemli, Lutfu Soylu, Fuat Atalay,Tevfik Ali Demirbas, Ali Demirbag, and Bahadir Celep. Severe gastrointestinal burn with hydrochloric acid; J Res Med Sci. 2013 May; 18(5): 449-452.

8. McCauley C E, Steed D L, Webster M V, Late sequele of gastric acid injury, Am J Surg 1985 ; 149:412-415

9. Zargar SA, Kochhar R, Nagi B, Mehta S, Mehta SK. Ingestion of corrosive acids. Spectrum of injury to the upper gastrointestinaltract \& natural history. Gastroenterology 1989: 97:702 - 707.

10. Cattan P, Munoz- Bongrand N, Berney T, Halimi B, Sarfati E, Celerier M. Extensive abdominal surgery after caustic ingestion. Ann Surg 2000; 231: 519-523

11. Boseniuk S, Rieger C. acute oral acetic acid poisoning--case report. Anaesthesiol Reanim. 1994;19:80-82.

12. Anderson, K.D, Rouse, T.M, Randolph, J.G. A controlled trial of corticosteroids in children with corrosive injury of the esophagus. N Engl J Med. 1990;323:637640. 